\section{O mal-estar da}

\section{teoria: demissão}

intelectual na

\section{aurora da}

cibercultura ${ }^{1}$

\begin{abstract}
RESUMO
0 presente trabalho trata da crise que atinge a teoria social no referente à reflexão sobre a lógica da civilização produzida pelas tecnologias digitais e do virtual. De acordo com 0 autor, a teoria social contemporânea perdeu a capacidade de apreender a lógica das coisas, bem como a natureza e os rumos da nova sociedade tecnológica.
\end{abstract}

\section{ABSTRACT \\ This work deals with the crisis undergone by contemporary social theory which seems to have lost its ability to cope with the logic as well as the nature and the direction ruling our present technological society. \\ PALAVRAS-CHAVE /KEY-WORDS \\ - Teoria Social (Social Theory) \\ - Sociedade (Society) \\ - Novas Tecnologias (New Technologies)}

\section{Eugênio Trivinho²}

Prof. Universidade Católica de Santos
1 Crise da teoria

A TEORIA SOCIAL, no que concerne à reflexão sobre a lógica da civilização gestada pelas tecnologias digitais e do virtual, vive uma de suas mais profundas crises. Se o fato não é novidade no âmbito da elaboração estritamente conceitual, assim o é, porém, na mesma intensidade em que em muitos setores acadêmicos a natureza dessa crise - conforme o que será exposto mais adiante - também não tem sido muito digna de interesse, e isto tanto mais no nível de profundidade que ela realmente requer.

No transcorrer da segunda metade do século XX, presenciaram-se, no âmbito das Humanidades, a corrosão irreversível do labor teórico no que se refere à sua relação com o tempo e ao seu alcance socioepiste mológico e histórico, bem como a acelerada deterioração de seu arranjamento como sistema e de sua relação umbilical com as grandes metanarrativas filosóficas, políticas e econômicas (vale dizer, com a tradicional lógica das teleologias e com a utopia moderna de emancipação da humanidade). De um só golpe, constam implicadas aí a longevidade, a totalidade e a universalidade (e, não raro, a cientificidade) como premissas prioritárias de legitimação histórica da produção do pensamento. A tais tendências, a última década acrescentou, em particular, a sua cota: a ampla e inusitada suspensão, na esfera desse fazer teórico, de toda e qualquer preocupação com a politização da realidade, no que toca à forma corrente de organização desta, fincada na tecnologia de ponta, redundou num obscuro expurgo da crítica. A linguagem dessa proscrição é 
solene e encaminhada num único refrão: a crítica não tem mais mercado.

No conjunto, trata-se de um abalo de monta. A teoria social contemporânea - herdeira, em grande medida ainda, do modelo tradicional e moderno de visão e sensibilidade de mundo - perdeu a capacidade de apreender a lógica das coisas, bem como a natureza e os rumos da sociedade tecnológica. O real, totalmente pulverizado e reconstruído pela técnica, passou a suplantá-la.

\section{Mal-estar na cultura e mal-estar da teoria}

Esses fatores de contexto perfazem, em linhas gerais, o mal-estar hoje vivido pela teoria. O mal-estar da teoria é, obviamente, um mal-estar na teoria, não na acepção de um mal-estar num âmbito abstrato, contraposto ao âmbito concreto da existência (um "mal-estar na prática"), mas na acepção de um mal-estar na cozinha da própria teoria, no coração de sua produção, aí onde se explica como, por que e para que ela é produzida.

A metáfora do mal-estar - que remonta à área médica, sabe-se, mas que aqui é tomada no limite de sua expressão figurada - tornou-se conhecida a partir da publicação do livro de Freud, Das Unbehagen in der Kultur, em 1930. ${ }^{3}$ Desde então, vários autores a empregaram para significar, em algum campo particular de estudos, certas propriedades relativamente equiparáveis àquelas abordadas por Freud. Mutatis mutandis, é o que convém igualmente realizar em relação aos dissabores vividos pela teoria na sociedade tecnológica atual. Ao que tudo indica, a metáfora ainda não foi utilizada para essa qualificação. É justo o momento, dadas as peculiaridades do tipo de pensamento social doravante promovido e de sua relação com as tendências do mundo tecnológico.

Sem nenhuma intenção de ensaiar qualquer passo em direção a uma psicanálise do mal-estar da teoria, uma sucinta relação entre os dois mal-estares pode ser traçada como segue, ao modo de teses:

(a) O fenômeno vislumbrado por Freud, embora marcado por injunções e interstícios eminentemente concretos, confunde-se com a universalidade ontológico-abstrata da cultura e, através dela, com o próprio processo civilizatório. $\mathrm{O}$ mal-estar da teoria é um fenômeno pontual e locado, embora não tanto sazonal quanto se mostre à primeira visada, eis que sua evidência não esconde a ocorrência de processos devastadores de longevidade indeterminada (conforme se observa mais abaixo).

(b) Com efeito, da mesma forma que, pela complexização das necessidades técnicas, um domínio no campo do saber multiplica seus próprios ramos particulares e relativamente autônomos de sustentação; da mesma forma que uma ação, por suas necessidades intrínsecas e de contexto, se desdobra em muitas práticas estratégicas em proveito de sua preservação e desenvolvimento; da mesma forma que, em outro registro, células cancerosas se projetam em suas próprias metástases, assim também o mal-estar genérico particulariza-se em diferentes formas de manifestação, ao mesmo tempo que delas se nutre. Aqui e alhures, do nível molecular e concreto à dimensão mais aberta e abstrata, patenteia-se a sua face, como uma sombra que insiste em cumprir seu direito à existência, enquanto os valores correntes se prontificam sobejamente em denegá-lo. Nessa perspectiva, o mal-estar da teoria é, no fundo, uma protuberância, no âmbito da criação intelectual, do malestar que se espraia por dimensões inaferíveis do próprio mundo tecnológico avançado.

(c) Note-se, no entanto, uma 
modulação decisiva no quadro desse paralelismo. Do ponto de vista da teoria psicanalítica, a lógica do malestar compreende, em quaisquer casos aventáveis, uma tensão compulsória e inelidível. No que concerne ao mal-estar aqui abordado, a lógica é diametralmente distinta: o mal-estar se manifesta num (e em virtude de um) vácuo de tensão. A tensão, nesse âmbito, não se apresenta como um fardo culturalmente herdado; ela é, antes, um elemento previsto e provocado em nome de uma certa política simbólica, a política da reflexão teórica, feita no exclusivo interesse de sua própria politização em relação ao real. Há, nesse mister, algo de necessariamente voluntário e facultativo, aquilo que, no essencial, se confunde com a enunciação e implementação de um projeto existencial. Trata-se de uma tensão exclusivamente expressa pela taxa interna de criticidade da elaboração teórica, bem como pelo grau de inclinação dialeticamente negativa, produtivamente contestatória dessa elaboração em relação à organização do real - grau de inclinação que é produto direto da própria intensidade da presença da categoria da crítica no labor reflexivo. Esse apontamento enfatiza o que não pode ser olvidado: a crítica é mais que um mero ingrediente constitutivo dos meandros da teoria; representando uma mediação mais avançada na elaboração teórica - mais-mediação que reescalona todos os pertences desse fazer -, ela reflete certa relação de tensão necessária com a forma e com os fluxos do mundo. Nessa medida, do mesmo modo que uma crítica sem fundamentação teórica e sem renovação epistemológica é um produto fadado à atrofia, uma reflexão teórica que não encerre a mais-mediação da crítica é uma construção desprovida de potencial de fissão. E o que não possui tensão interna apresenta-se inócuo, não produz nenhum movimento e seu destino resulta sempre viciado: converge para o interesse das estruturas existentes. Um pensamento amputado da categoria da crítica é, mais que isso, um pensamento suicida - no pior sentido: veladamente messiânico - e perigoso: comprometido em sua própria imunidade, deixa aberta a porta para o adensamento e a legitimação de todo e qualquer desejo teórico e pragmático de promiscuidade com a forma e com os fluxos do mundo.

A reflexão teórica perde, nesse caminho, o seu maior sentido, o sentido que vale a sua existência: o de vigorar justamente como contraponto (tanto mais radical quanto possível) àquilo para o que ela estranhamente agora conflui. Em tais condições, é a reflexão que, antes de tudo, se despolitiza - vale pontuar, antes mesmo de ela despolitizar a sua relação com a forma do existente e com os elementos constitutivos deste -, aprofundando-se ainda mais a defasagem no âmbito de sua estruturação interna e de seu desenvolvimento epistemológico, bem como, conseqüentemente, o seu despreparo social.

É o que sói acontecer hoje em dia. Quase toda a produção teórica sobre a lógica da sociedade organizada pela cibercultura e pelo cyberspace, tendo suspendido por demais a categoria da crítica, já não tem como parâmetro precípuo nenhuma produção de tensão com o universo infotecnológico e virtual vigente. $\mathrm{Na}$ pior das hipóteses, camuflam-se até as tensões concretamente em jogo. Em geral, quer-se mais seguir o fluxo, tomálo, fazer parte dele, a pretexto de alguma produção teórica genuína. Nos casos de adesão involuntária à forma do existente, o resultado é idêntico: esclerose múltipla do pensamento.

O mal-estar genérico da cultura atinge o fazer teórico quando, singularmente, afeta justo a capacidade de fundação de uma epistemologia de contestação e, de resto, o potencial de contraponto da própria epistéme; em suma, quando afeta a criatividade estratégica para a tensão necessária, bem como o produto desta 
criatividade, destinado ao esclarecimento público. Nesse ponto, o mal-estar da teoria não comparece senão como o desdobramento, no campo dos estudos sobre a sociedade tecnológica atual, de um fenômeno tão antigo quanto bem conhecido: a marcescência dos pendores de negação conceitual conseqüente.

(d) Do mal-estar na civilização ao mal-estar da teoria, constata-se, pois, dessa perspectiva, um único fio condutor, fundamento de um deslocamento aniquilador: lá, o padecimento revoltoso e a acomodação transpolítica das pulsões em geral; aqui, a debilitação avançada da pulsão crítica. Implica-se aí, no fundo, um mesmo processo de apaziguamento da consciência e da visão de mundo, numa intensidade apenas um tanto mais acentuada. Em ambos os casos, as pulsões acabam, mesmo quando a contragosto, por alinhar-se à forma e aos fluxos do existente, em que pese o fato de se observarem diferenças fundamentais de operação: lá, as pulsões barradas pelo interdito cultural não desaparecem; sobrevivem na dimensão psíquica da fantasia, de onde vislumbram continuamente suas chances de realização no porvir; aqui, seduzida, a pulsão crítica simplesmente se esfuma, segundo os ditames atuais da "servidão voluntária", sem deixar nenhum resíduo, nenhum fantasma, na forma de uma "consciência culposa", remoto termômetro que, ao menos, indicaria que alguma coisa não caminha bem - e, com essa dissipação, vão-se também todas as possibilidades de reverberação dessa pulsão, num espetáculo de desaparecimento tão intrigante quanto deprimente -; uma vez mais, lá, o malestar é o preço individualmente pago pela adaptação ao processo de domesticação genérica das pulsões interditas e também pelo "alijamento" destas da vida de vigília; aqui, o mal-estar é, para a reflexão teórica, em sua dimensão social-histórica, o preço pago pela domesticação das propensões contestatórias e pela expulsão destas da cena do pensamento e do campo epistemológico da cultura.

Em estrito alinhamento às tendências tecnológicas correntes - vale dizer, clamando por elas, na verdade, por apostar piamente em seu suposto potencial de democracia, liberdade e emancipação -, a teoria social, doravante tecida pelo neo-humanismo, pelo neo-iluminismo e pelo neoliberalismo cibertecnológicos e, por eles, prazerosamente entregue às armadilhas sedutoras do neopositivismo (como se transformada também numa festa rave, numa orgia tecno, ao estilo discreto), pode assim expressar um orgulho invertido: traição ao melhor de seu percurso histórico recente. (Repõe-se aqui, portanto, a questão da tensão no âmbito da reflexão teórica contemporânea, mas uma tensão de outra natureza, aquela que se observa entre essa reflexão e uma esplêndida parte da própria história social da teoria, alinhada à crítica. É desse ponto de vista que, aliás, se tece a argumentação em curso.)

(e) Numa locução peremptória, o malestar atual da teoria é, todo ele, em síntese - não seria esquemático dizê-lo -, derivado do expurgo da crítica como instrumento de trabalho e de vida, conseqüência direta da denegação naïve da categoria do político. (De se lembrar, en passant, que a validade dessa conclusão não se restringe apenas ao âmbito ora enfocado.) Não por outro motivo, o mal-estar da teoria abarca também o vácuo atual de invenção de mal-estares produtivos no e em relação ao universo infotecnológico e virtual vigente. $\mathrm{Na}$ forma e com a força pela qual se põe, o mal-estar da teoria não representa senão a alegre rendição ao próprio mal-estar da cultura, na forma teorizada por Freud - fato que não colabora senão para aprofundar a característica da própria cultura contemporânea como cultura do mal-estar. ${ }^{4}$

Dissuasão da crise 
Os cinco excursos anteriores perfazem bem uma imagem cadente: demissão intelectual na aurora da cibercultura. ${ }^{5}$

Essa singularidade da época e a sua problemática de fundo apresentam, em situações mais paroxísticas, nuanças capciosas, que sugerem a inexistência mesma dessa demissão e da crise que ela representa. Se, de um ângulo, o mal-estar da teoria começa, nos termos antes firmados, quando a reflexão de vocação social e cultural - enfatize-se: no âmbito dos estudos sobre o fenômeno cibertecnológico - torce o nariz para as categorias da crítica e do político, de outro ângulo, algumas tendências do pensamento contemporâneo, dentro e fora do cenário brasileiro, deixam entrever que o malestar enceta quando a categoria da crítica, considerada a priori démodée, pretende permanecer no jogo da produção teórica ou, na pior hipótese, entrar "de novo" no jogo. Segundo tal premissa, extraindo-se a crítica dos afazeres conceituais - quase como que ao modo de uma incisão para a retirada de um tumor maligno -, equacionase todo o problema.

À primeira vista, parece forjar-se aí um confronto de posições, como se a problemática abordada envolvesse, internamente, dois tipos diferentes de malestar. Essa impressão é um subproduto típico e dissuasivo do abraço à causa da denegação da categoria da crítica. Sob o prisma da defesa desta, no entanto, trata-se, no fundo, de duas fases de um mesmo processo: a segunda apenas representa o momento terminal da primeira, o qual, longe de rimar com morte, culmina, antes, no excelso apogeu de um modelo monopolista de teoria feliz, satisfeita consigo própria e deslumbrada com as tendências cibernéticas do mundo, como se à teoria, a essa altura da secularização do pensamento, fosse dado o direito de viver (algo assim como) uma plena adolescência histórica. É uma situação que goza de regalias triunfais: é como se, onde a tecnologia informática (em todas as suas variantes) entra pela porta da frente, a crítica fosse convidada a se retirar pela porta dos fundos, com a agravante de ter que fazê-lo sem nenhum direito e ainda sob humilhação, como se ela fosse, de fato, uma ninharia ou algo assim como um cão sem dono.

A questão implica, portanto, uma gravidade de maior quilate. O mal-estar real da teoria porta uma idiossincrasia: ele comparece de maneira obliterada para a própria teoria, a ponto de esta reconhecer a existência do mal-estar exclusivamente numa situação contrária àquela em que de fato se manifesta o mal-estar. Para todos os efeitos, então, é como se, para a teoria, não se processasse nenhum mal-estar - em que pese a intensa exalação de signos peculiares, facilmente identificáveis, da carência da categoria da crítica e do político, exalação da qual a argumentação em curso já deve ter oferecido demonstrações suficientes e que, ainda assim, convém remodelar, mesmo sob o risco de eventual reiteração:

(a) debilitação estrutural, encoberta por um discutível potencial de alcance simbólico-cognitivo;

(b) crise de identidade, sob o aparente amparo da boa e regular fluidez das coisas, em meio à confusa explosão da diversidade no campo da produção intelectual;

(c) aplacação epistemológica, às expensas até mesmo da incorporação da terminologia social promovida pelos discursos mediáticos;

(d) aceitação apriorística da organização cibertecnológica da vida, sob o álibi do necessário envolvimento com a empiria atual ou da imprescindível previsão desta nos meandros do fazer teórico.

Eis um ponto fundamental, corolário requintado da ausência de tensão anteriormente apontada: a denegação do 
mal-estar por parte daquilo mesmo que o desencadeia não é senão o indício de um aprofundamento mais acentuado do próprio mal-estar, expressão fiel - grife-se, de outro ângulo - do alto grau de anuência em relação ao próprio mal-estar genérico e historicamente cumulativo da civilização. A teoria social contemporânea, cega para o logro por ela mesma proposto, comparece na cena da cultura sem a medida de sua própria fragilidade e da perda de sua própria imunidade. É justamente assim que o mal-estar aqui abordado acaba por se perpetuar sem impor ao fazer teórico maiores constrangimentos adicionais.

A gravidade da situação aumenta quando, reescalonando-se o prisma de observação, se leva em conta, enfim, que o enorme mal-entendido que aí se joga a respeito do significado da categoria da crítica e de seu papel público não é senão, vis-à-vis, um diminuto lance do profundo mal-entendido acerca da função socialhistórica que cabe à própria Universidade desempenhar pelo crivo das Humanidades.

\section{Razões de contexto}

\section{Drama da crítica}

As vicissitudes da crítica - mais além de sua infundada atrelagem exclusiva à responsabilidade individual dos intelectuais e à singularidade da produção teórica atual no âmbito de estudos apontado - explicamse, não obstante, pelo seu contexto tecnológico, social-histórico e cultural contemporâneo.

A esse respeito, todos os fatores reunidos na exposição anterior são ainda lacunares, carecendo, pois, não somente de complementos explanativos, mas sobretudo de uma modulação fundamental e, bem assim, de um reescalonamento analítico.

Notoriamente, o século $X X$ testemunhou o desenrolar cumulativo de três fenômenos socioculturais majoritários e de seus respectivos debates internacionais. São eles, expressos nas temporalidades de maior concentração destes últimos, em períodos arredondados (por mais forçosos e esquemáticos que reconhecidamente o sejam): de 1940 a 1960, cultura de massa; de 1970 a 1980, cultura pós-moderna; de 1990 até o momento, cibercultura.

Nesses fenômenos e debates -, processados, vale explicitar, em pouco mais de cinco décadas -, a técnica e as redes mediáticas comparecem como objeto direto, pano de fundo e/ou horizonte. O desenvolvimento social da técnica e da comunicação concorreram para conferir a todos os valores um peso relativamente idêntico, em nome de uma canhestra idéia de democracia. Nesse sentido, ele contribuiu para realizar - sob a égide de uma sutileza repressiva, ao frêmito de um "toque de recolher" não anunciado, mas asfixiante - uma espécie de niilismo às avessas, que passou a fechar, em todos os recônditos, com status quo high tech. A essa configuração de fatores se sobrepuseram a cibercultura e o cyberspace, que rearticularam e indexaram o horizonte e o ritmo das tendências mediáticas então em voga. Quanto à questão da pós-modernidade, embora as discussões internacionais sobre o assunto já tenham encontrado o seu ponto de saturação - com o mesmo vigor com que foram originalmente desencadeadas -, os fatos e processos para os quais elas chamaram a atenção permanecem à frente de todos.

Diante desse mutante cenário, dessa contínua e rápida oscilação de referenciais, sobredeterminada pela corrosão em cadeia dos grandes empreendimentos teóricoepistemológicos (filosóficos, políticos e econômicos - teleológicos ou não -, matriz marxista à frente), é ponderável admitir que a crítica - mais que a própria teoria - não teve o devido tempo para se refazer dos traumas contraídos, ou mesmo não o quis. Egressa de um tal contexto gelatinoso, vendo tudo desmoronar e cambiar de 
forma à sua frente, inclusive o que se entende por pensamento de vocação social e cultural, a crítica ainda não logrou construir para si uma nova identidade; sequer conseguiu se reencontrar consigo mesma. Fundamentalmente, ela ainda não se houve, por exemplo, com as décadas tecnológicas de 80 e 90; não metabolizou consistentemente o percurso e a herança cultural dessas décadas: descontruções, fragmentações, flutuações, relativismos, aporias. Ficou literalmente para trás, de maneira que, no presente, sua condição é realmente assaz precária.

Consideradas tais razões de contexto, não é, pois, por desídia, muito menos por acaso, que a crítica, quando confrontada com questões pertinentes ao universo infotecnológico e virtual vigente, com todos os atributos de eficiência e funcionalidade deste, padeça de uma hesitação surpreendente - disto que até se poderia denominar uma "labirintite teórica" - e, na pior das conseqüências, de uma intensa crise de auto-anulação. Esse fato, ao mesmo tempo que demarca a clara reverberação da rápida dialética do socialhistórico no âmbito da elaboração teórica, quer dizer, na cozinha da (re)criação da crítica, patenteia o que - com as escusas pelo abuso de metáforas não tanto identitárias às Humanidades - se espera seja o processo de convalescença da crítica. Ainda assim, é a própria crítica, lembre-se, que recomenda a suspeita em relação a qualquer dado do mundo (isto é, do mundo tal qual ele tem sido): pois uma leitura atenta das entrelinhas do contexto revela que, ao fim de mais de dois milênios, a crítica teórica, tão outrora largamente combativa, diante do mais vigoroso processo sumário de falência a que está sendo compulsoriamente conduzida, pede não somente socorro, mas também misericórdia - ainda que ela jamais devesse fazê-lo.

Esta cena dramática pode ser retocada com outras palavras, a título de encerramento da argumentação. Em todas as épocas, sempre se depositou na tarefa da crítica teórica uma proeminente esperança de resistência. Por certo, a crítica não significa necessariamente negação cabal de uma totalidade objetal. (Quem trabalha com este postulado ainda não compreendeu as nuanças fundamentais da crítica e, por isso, segue repondo uma falsa questão.) A crítica, porém - seja qual for a sua modalidade e o seu perfil e seja em qual nível de abstração conceitual opere -, sempre implicará alguma ruptura com aquilo sobre o que se projeta. A crítica teórica que a conta-gotas ainda se produz (com embasamento ou não na lógica das teleologias) continua trazendo no bojo esses traços fundamentais (resistência, ruptura), doravante com uma responsabilidade um tanto mais acentuada, em função de estar em jogo a luta contra a sua própria extinção, num contexto em que agora ela precisa também se desembaraçar do logro dissuasivo que lhe é lançado pela própria teoria social. Com efeito, quando poucos ouvidos dão a devida atenção até mesmo à necessidade de uma categoria renovada da crítica, isso não conforma apenas a situação indicial do quanto a teoria se encontra docilizada pelo contínuo desfrute do ópio mercantil; é porque, mais profundamente, uma destruição invisível talvez já tenha de fato cumprido o seu papel, de maneira que pouca (ou já nenhuma) esperança se pode acalentar no sentido indicado. Que o real não seja otimizado pela radicalização proposital de uma hipótese sombria, dependerá exclusivamente daqueles a quem a história presente faz repousar os rumos teóricos da Universidade em todas as partes do mundo . 6

\section{Notas}

10 presente artigo corresponde, com pequenas modificações formais, à Apresentação I de uma obra recentemente lançada pelo autor, 0 mal-estar da teoria: a condição da crítica na sociedade tecnológica atual, São 
Paulo: Editora Quartet, 2001.

2 Ensaísta, Doutor em Ciências da Comunicação pela Escola de Comunicações e Artes da Universidade de São Paulo, leciona no Programa de Pós-Graduação da mesma instituição e no Programa de Pós-Graduação em Comunicação Social da Universidade Católica de Santos, e coordena o Grupo de Trabalho "Comunicação e Sociedade Tecnológica da COMPÓS - Associação Nacional dos Programas de Pós-Graduação em Comunicação. É autor, entre outros, de Redes: obliterações no fim de século (Annablume / FAPESP, 1998), Contra a câmera escondida: estruturas da violência soft (Editor-autor, 1998), e "Cyberspace: crítica da nova comunicação", São Paulo, Biblioteca da ECA/USP, 1999, 466 págs. (a sair pela Editora Annablume).

3 Em português, veja-se Freud, Sigmund, "O mal-estar na civilização", in Edição Standard Brasileira das Obras Psicológicas Completas de Sigmund Freud, Rio de Janeiro: Imago Editora, Volume XXI, 1974, pp. 81-171.

4 Cf. Trivinho, Eugênio, "As formas do mal-estar na era tecnológica avançada", in Cabeda, Sonia e Carneiro, Nadia Virginia (orgs.), 0 mal-estar no fim do século XX: seminário interdisciplinar, Feira de Santana: Sagra, 1997, p. 29-37.

5 Para fazer uma alusão expressa ao livro de Alain Caillé, A demissão dos intelectuais: a crise das ciências sociais e o esquecimento do factor político, Lisboa: Instituto Piaget, s/d (0 original francês é de 1993). 0 subtítulo do presente texto foi inspirado na Introdução dessa obra (pp. 11-42.). Guardadas as diferenças de posição teórica em relação ao método de desenvolvimento do saber e de interpretação dos dados do real, ao passado da teoria social, ao contexto social e cultural contemporâneo, e às necessidades intrínsecas e ao papel das ciências sociais nesse contexto, observe-se que Caillé identifica com propriedade e demonstra exemplarmente o mesmo problema fundamental aqui abordado: a amnésia cultural em relação ao vetor político (ou normativo) durante o labor teórico-conceitual em Humanidades. Caillé abarca, especialmente, em seu discurso, a economia, a sociologia, a filosofia política e a história produzidas nas últimas décadas do século XX, e a sua crítica se dirige às perspectivas teóricas de Karl Popper, Francis Fukuyama, Richard Rorty e outros.
6 A esse respeito, deve pesar sobremaneira a emergente mobilização política mundial em resistência à globalização econômico-financeira e ao neoliberalismo, legitimados pelo Consenso de Washington e pelas deliberações do Fórum Econômico Mundial, anualmente realizado em Davos, Suíça. Visto o problema por essa perspectiva, não é difícil reconhecer que as propensões de contraponto hoje grassam por todos os lados. Ocorre que elas não se traduzem na formalização e conseqüente proposição pública de uma crítica teórica renovada e consistente no que concerne ao âmbito das tecnologias informáticas, da cibercultura e do cyberspace. É como se, nesse âmbito, tudo fosse encarado como uma maravilha fora de contexto. 0 dilema, portanto, não é da ordem do movimento prático do real ordinário. 0 problema é, in totum, a teoria social. Por certo, a crítica à política neoliberal e à globalização econômico-financeira é, constitutivamente, uma crítica - direta ou indireta - ao contexto tecnológico e mediático hegemônico que Ihes dá sustentação. Mas, sem uma melhor modulação teórica e uma mediação epistemológica atinentes à empiria, às estruturas e processos, aos dados específicos do universo infotecnológico e virtual vigente, tudo soa como se não existisse categoria da crítica nessa área de estudos, quanto mais uma crítica auto-reflexiva em relação aos seus princípios de referência.

A se lembrar, com efeito, que a globalização econômico-financeira não deixa de ser, em última instância, um epifenômeno da comunicação eletrônica, e o neoliberalismo, um tipo de economia política e de administração do Estado que combina com o modelo democrático formal de funcionamento social pleiteado pelos próprios media, eis que a estes se apresenta crucial um cenário jurídico-político que preveja um vínculo inextricável entre as liberdades civis - nas quais se deve incluir a liberdade de ação empresarial - e a autoregulação da sociedade pelo mercado.

Se as mobilizações políticas mundiais contra a globalização econômico-financeira e o neoliberalismo não estimularem os ânimos na direção antes sugerida, ter-se-á uma idéia do quão realmente sedutor se tornou 0 universo infotecnológico e virtual vigente, do quão putrefato se encontra o pensamento social contemporâneo sobre este universo e do quão minado e digno de lamento já é o legado teórico que o presente deixará para as próximas gerações. A vingar totalmente 0 que se amolda ao ufanismo tecnológico hodierno, o presente livro não terá sido em vão - ou, ao contrário, o terá sido completamente. 